\title{
AN IMPROVED SYNTHESIS OF 2-(PYRID-2'-YL)-1,10-PHENANTHROLINE TRIDENTATE TERPYRIDYL LIGAND
}

\author{
ZIBASERESHT R. ${ }^{1,2^{*}}$, KARIMI P. ${ }^{1,3}$, MOHIT-AZAR S. ${ }^{1,4}$, AMIRLOO M.R. ${ }^{1}$ AND AZIMI M. ${ }^{1}$ \\ 1Biomaterial Laboratory, Department of Toxicology, Faculty of Medicine, AJA University of Medical Sciences, Tehran, Iran. \\ 2Department of Chemistry and Physics, Faculty of Sciences, Maritime University of Imam Khomeini, Noshahr, Mazandaran, Iran. \\ 3Department of Chemistry, Faculty of Sciences, Islamic Azad University- Tehran North Branch, Tehran, Iran. \\ 4Department of Chemistry, Faculty of Modern Sciences and Technologies, Islamic Azad University- Pharmaceutical Sciences Branch, Tehran, \\ Iran. \\ *Corresponding Author: Email- rzi12@uclive.ac.nz
}

Received: November 28, 2013; Accepted: December 26, 2013

\begin{abstract}
An improved multistep synthetic route for preparation of a tridentate terpyridyl ligand, 2-(pyrid-2'-yl)-1,10-phenanthroline, has been reported. In the first step, a Skraup quinoline synthesis using $m$-toluidine and glycerol was employed. The mixture of 5-and 7-methylquinoline which was obtained was selectively nitrated at 8-carbon position of the 7- derivative. The methyl group in 7-methyl-8-nitroquinoline was then oxidized to an aldehyde followed by a reduction of the nitro group to an amine group. The last step involved a Friedländer condensation of the amino aldehyde with 2-acetylpyridine to obtain the final product with overall high yield. All products were fully characterized.
\end{abstract}

Keywords- 2-(pyrid-2'-yl)-1,10-phenanthroline, synthesis, Skraup, Friedländer

Citation: Zibaseresht R., et al (2013) An Improved Synthesis of 2-(pyrid-2'-yl)-1,10-phenanthroline Tridentate Terpyridyl Ligand. International Journal of Chemical Research, ISSN: 0975-3699 \& E-ISSN: 0975-9131, Volume 5, Issue 1, pp.-153-158.

Copyright: Copyright@2013 Zibaseresht R., et al. This is an open-access article distributed under the terms of the Creative Commons Attribution License, which permits unrestricted use, distribution and reproduction in any medium, provided the original author and source are credited.

\section{Introduction}

In general, oligopyridines and 2,2':6',2"-terpyridine (tpy) in particular, have received considerable attention in supramolecular chemistry [1].

As it has been reflected in the literature, substituted $2,2^{\prime}: 6^{\prime}, 2^{\prime \prime}-$ terpyridines are promising building blocks for supramolecular systems [2] and there is great interest in their coordination with transition metals, [3-8] mainly due to their interesting photophysical properties $[9,10]$ and potential pharmaceutical applications $[11,12]$. Particular interest rests in 4'-substituted tpy-ligands and many substituents can be directly inserted using Kröhnke methodology [13]. The work of most groups has been concerned with attaching functional groups directly to the $C\left(4^{\prime}\right)$ of $2,2^{\prime}: 6^{\prime}, 2^{\prime \prime}$-terpyridine [14-24], principally, because of the ease of synthesis of the substituted terpyridine from the related aldehyde.

Although 2,2':6',2"-terpyridines bearing different functional groups at the 4'-position and at the outer pyridine rings have become an expanding field of terpyridine derivative preparation, [25-48] surprisingly, asymmetrically functionalized 2,2':6',2"'-terpyridine systems have been less studied.

The many interesting applications of functional metalcoordinating $2,2^{\prime}: 6^{\prime}, 2$ '"-terpyridine compounds in the fields of supramolecular and macromolecular chemistry as well as electrochemistry has resulted in an impressive growth in the number of novel synthetic procedures. Modern ring assembly and cross-coupling procedures ena- ble the well-directed introduction of different functionalities into almost every position of the terpyridine ring system. This could allow the incorporation of these chelating ligands into more complex architectures and would open avenues to novel materials in the fields of supramolecular, polymer or surface chemistry.

Currently, we are engaged in the design and construction of simple unsymmetrical substituted 2,2':6',2"-terpyridine compounds whose structures are essentially controlled by the planarity of the aromatic rings. An approach to the achievement of such goals is based on the assembly of suitable molecular components (building blocks) according to well-designed structural patterns.

Several tridentate ligands were considered for this purpose, but the tridentate terpyridyl 2-(pyrid-2'-yl)-1,10-phenanthroline (pyp) ligand was chosen, both because of the potential functionalisation in an asymmetrical fashion, and because of the ease with which the ligand can be synthesized [49].

Although the synthetic strategy of the ligand was explored some time ago, [49] but our interest in the ligand design using the ligand pyp led us to revisit some of its chemistry, with the intention of applying modern synthetic and spectroscopic techniques for preparation and characterization of the system.

Here, in this paper we report the results of an investigation on a modified and efficient multistep synthesis of terpyridyl pyp ligand which has a great potential of asymmetrical fictionalization for further usage as asymmetrical bridging ligands. 


\section{Materials and Methods Materials}

Reagent grade commercial compounds were used as starting materials, and their purity was checked by ${ }^{1} \mathrm{H}$ and ${ }^{13} \mathrm{C}$ NMR.

The $500 \mathrm{MHz}{ }^{1} \mathrm{H}$ NMR and ${ }^{13} \mathrm{C}$ NMR spectra were acquired on a Bruker-500 spectrometer. ${ }^{1} \mathrm{H}$ NMR and ${ }^{13} \mathrm{C}$ NMR chemical shifts are referenced to residual solvent resonances $\left(\mathrm{CDCl}_{3}, 7.25\right.$ and 77.01 ppm, respectively). Infrared spectra $(400-4000 \mathrm{~cm}-1)$ were obtained using a Shimadzu 8201PC Series FTIR interfaced with an Intel 486 PC operating Shimadzu HyperIR software. Spectra were obtained using diffuse reflectance method in solid KBr. GC-MS, LC-MS and Microanalyses were performed at Shahid Beheshti University of Medical Sciences.

Glycerol, $m$-toluidine, dimethylformamide dimethyl acetal, $\mathrm{NaIO}_{4}$, 2acetylpyridine were obtained from Aldrich and used without further purification. DMF was dried on molecular sieves and purged with $\mathrm{Ar}$ before use and kept under Ar after use. All other starting materials were obtained commercially and used as received.

\section{Syntheses}

The synthetic scheme is shown in [Fig-1].

\section{7-methylquinoline (1)}

In a round-bottom flask, $m$-nitrobenzene-sulfonate $(135 \mathrm{~g}, 0.6 \mathrm{~mol})$, glycerol (83.52 g, $0.92 \mathrm{~mol})$, and $m$-toluidine $(50.46 \mathrm{~g}, 0.47 \mathrm{~mol})$ were mechanically stirred. To this mixture was added a solution of $273.58 \mathrm{~g}(2.7 \mathrm{~mol})$ of $98 \% \mathrm{H}_{2} \mathrm{SO}_{4}$ and $61.5 \mathrm{~g} \mathrm{H}_{2} \mathrm{O}$ slowly. The addition was dropwise and the $\mathrm{H}_{2} \mathrm{SO}_{4} / \mathrm{H}_{2} \mathrm{O}$ solution had been cooled in an ice bath before the addition. During the addition, the mixture was mechanically stirred and the exothermic reaction was controlled with an ice bath when needed. Once the addition was completed, the solution was heated to reflux $\left(\mathrm{ca} .150^{\circ} \mathrm{C}\right)$ for 1 hour (Caution: spontaneous exothermicity!). The solution was then cooled in an ice bath, diluted with $330 \mathrm{~mL} \mathrm{H} \mathrm{H}_{2} \mathrm{O}$ and $43.08 \mathrm{~g} \mathrm{NaNO}_{3}$ were added slowly. The solution was then warmed $\left(\sim 70^{\circ} \mathrm{C}\right)$ for about $20 \mathrm{~min}$ to decompose the excess of $m$-toluidine. The solution was cooled again in an ice bath and $400 \mathrm{~g} \mathrm{KOH}$ were added slowly to increase the $\mathrm{pH}$ of the solution above $10(\mathrm{pH}>10)$. The solution was then purified using steam distillation. The clear distillate was cooled, saturated with $\mathrm{NaCl}$ and kept in the refrigerator for a couple of nights. The brown crude oil that formed was separated from the distillate using a separatory funnel. Then, the distillate was extracted with diethyl ether $(3 \times 200 \mathrm{~mL})$. The organic phases were collected, dried with $\mathrm{MgSO}_{4}$, and evaporated on a rotary evaporator. The resulting oil was then further purified using vacuum distillation: bp $91^{\circ} \mathrm{C}(3 \mathrm{mmHg})$ to give a $70 \%$ yield of 7 -Methylquinoline (based on GC-MS and ${ }^{1} \mathrm{H}$ NMR).

\section{7-Methylquinoline (1)}

${ }^{1} \mathrm{H}$ NMR $\left(500 \mathrm{MHz}, \mathrm{CDCl}_{3}\right) \delta 8.85(\mathrm{~d}, 1 \mathrm{H}), 8.07(\mathrm{~d}, 1 \mathrm{H}), 7.88(\mathrm{~s}, 1$ H), $7.68(\mathrm{~d}, 1 \mathrm{H}), 7.35(\mathrm{~m}, 2 \mathrm{H}), 2.55(\mathrm{~s}, 3 \mathrm{H}) . \mathrm{MS}: \mathrm{m} / \mathrm{z}(\%): 143.3$ (100), 115.2 (29), 89.2 (14), 63.2 (14).

\section{5-Methylquinoline (2)}

${ }^{1} \mathrm{H}$ NMR $\left(500 \mathrm{MHz}, \mathrm{CDCl}_{3}\right) \delta 8.90(\mathrm{~d}, 1 \mathrm{H}), 8.28(\mathrm{~d}, 1 \mathrm{H}), 7.97(\mathrm{~d}, 1$ H), $7.58(\mathrm{t}, 1 \mathrm{H}), 7.39(\mathrm{~m}, 1 \mathrm{H}), 7.29(\mathrm{~m}, 1 \mathrm{H}), 2,65(\mathrm{~s}, 3 \mathrm{H})$.

\section{7-Methyl-8-Nitro-quinoline (3)}

A solution of $28.5 \mathrm{~mL}$ of fuming $\mathrm{HNO}_{3}$ and $85.5 \mathrm{~mL}$ of $98 \% \mathrm{H}_{2} \mathrm{SO}_{4}$ was added dropwise at $-5^{\circ} \mathrm{C}$, to a mechanically stirred mixture of
$57.05 \mathrm{~g}(0.398 \mathrm{~mol})$ of 7 - and 5-methylquinoline (1+2) and $142.5 \mathrm{~mL}$ of $\mathrm{H}_{2} \mathrm{SO}_{4}$. Once the addition completed, the cool bath was removed and stirring was continued for $40 \mathrm{~min}$. The solution was then poured over ice and vacuum filtered once the ice was completely dissolved. Additional cold water was added to filtrate until no more precipitate appeared. The mixture was kept in the refrigerator overnight for precipitation completion. The precipitate was filtered, and then $95 \%$ $\mathrm{EtOH}(3 \times 100 \mathrm{~mL})$ was used to wash the solid. The solid was dried under vacuum to afford $51.80 \mathrm{~g}(69 \%, 99 \%$ based on 7 Methylquinoline) as a white powder. M.p. $=182-183^{\circ} \mathrm{C} .{ }^{1} \mathrm{H}$ NMR $\left(\mathrm{CDCl}_{3}\right) \delta 8.98(\mathrm{dd}, 1 \mathrm{H}), 8.22(\mathrm{dd}, 1 \mathrm{H}), 8.87(\mathrm{~d}, 1 \mathrm{H}), 7.49(\mathrm{~m}, 2 \mathrm{H})$, 2.56 (s, $3 \mathrm{H})$. IR (KBr): $\widetilde{v} / \mathrm{cm}^{-1}=3077 \mathrm{w}, 1630 \mathrm{w}, 1597 \mathrm{msh}, 1569$ m, 1531 ssh, 1503 ssh, 1464 m, 1447 m, 1433 m, 1381 msh, 1356 msh, 1321 msh, 1229 w, 1202 w, 1145 wsh, 1067 w, 1040 w, 996 w, 959 w, 883 ssh, 844 ssh, 808 ssh, 740 w, 683 w, 647 msh. MS: $\mathrm{m} / \mathrm{z}(\%): 188.1$ (100), 171.1 (70), 158 (57), 141 (91), 130.1 (90), 115.1 (90), 103.1 (45), 77.1 (53). Anal. Calc. for $\mathrm{C}_{10} \mathrm{H}_{8} \mathrm{~N}_{2} \mathrm{O}_{2}$ (188.18): C 63.82, H 4.28, N 14.89\%; found: C 64.47, H 4.65, N $14.98 \%$.

\section{7-[ $\beta$-trans-( $N, N$-dimethylamino)ethenyl]-8-nitroquinoline (4)}

A solution of $3(3.0 \mathrm{~g}, 16.0 \mathrm{mmol})$ and $\mathrm{N}, \mathrm{N}$-dimethlformamide dimethyl acetal $(5.7 \mathrm{~g}, 6.4 \mathrm{~mL}, 48 \mathrm{mmol})$ in dry DMF $(5 \mathrm{~mL})$ was degassed with argon for $30 \mathrm{~min}$ and then heated to $140{ }^{\circ} \mathrm{C}$ under argon for $18 \mathrm{~h}$. The reaction mixture was cooled to room temperature overnight. To a red crystalline material which was obtained was added water $(50 \mathrm{~mL})$. The mixture was then extracted with $\mathrm{CH}_{2} \mathrm{Cl}_{2}$ $(5 \times 20 \mathrm{~mL})$ and the combined organic layers dried over magnesium sulfate and concentrated in vacuo. The red crystalline material was then washed with $\mathrm{n}$-hexane $(2 \times 20 \mathrm{~mL})$ to afford $4(3.7 \mathrm{~g}, 95 \%)$ as a red crystal. M.p. $=182-184^{\circ} \mathrm{C}$. (lit. m.p $\left.=181-183^{\circ} \mathrm{C}[50]\right){ }^{1} \mathrm{H}$ NMR $\left(\mathrm{CDCl}_{3}\right) \delta 8.83(\mathrm{dd}, 1 \mathrm{H}), 8.02(\mathrm{dd}, 1 \mathrm{H}), 7.60(\mathrm{q}, 2 \mathrm{H}), 7.29(\mathrm{~d}, 1 \mathrm{H})$, $7.10(\mathrm{~d}, 1 \mathrm{H}), 5.06(\mathrm{~d}, 1 \mathrm{H}), 2.93(\mathrm{~s}, 6 \mathrm{H}) .{ }^{13} \mathrm{C} \mathrm{NMR}\left(\mathrm{CDCl}_{3}\right) \delta$ $151.66,144.35,141.87,140.63,135.20,132.13,128.07,124.02$, 121.59, 119.58, 87.62, 40.22. IR (KBr): $\widetilde{v} / \mathrm{cm}^{-1}=3058 \mathrm{w}, 2924 \mathrm{w}$, $1641 \mathrm{~m}, 1606 \mathrm{msh}, 1526 \mathrm{ssh}, 1385 \mathrm{ssh}, 1372 \mathrm{ssh}, 1315 \mathrm{ssh}, 1272$ m, 1203 m, 1170 m, 1110 ssh, 1063 m, 1047 m, 972 m, 950 m, 878 msh, 831 msh, 805 msh, 771 msh, 735 w, 684 msh, 654 msh. MS: m/z (\%): 243.1 (23), 226.1 (55), 183.1 (36), 169.1 (38), 155.1 (34), 142.1 (100), 115.1 (69), 86.1 (41). Anal. Calc. for $\mathrm{C}_{13} \mathrm{H}_{13} \mathrm{~N}_{3} \mathrm{O}_{2}$ (243.26): C 64.19, H 5.39, N 17.27\%; found: C 64.09, H 5.41, N $17.21 \%$.

\section{8-Nitro-7-quinolinecarbaldehyde (5)}

$\mathrm{NaIO}_{4}(35.2 \mathrm{~g}, 164.4 \mathrm{mmol})$ was added to a solution of $4(10.0 \mathrm{~g}$, $41.1 \mathrm{mmol})$ in $50 \%$ aqueous THF $(600 \mathrm{~mL})$. The yellow solution was stirred at room temperature for $4 \mathrm{~h}$ during which time a yellowbrown mixture was obtained. The insoluble products were removed by filtration and washed with EtOAc. The solvent was evaporated in vacuo and $\mathrm{CH}_{2} \mathrm{Cl}_{2}(50 \mathrm{~mL})$ was added. The organic layer was washed with saturated aqueous $\mathrm{NaHCO}_{3}(2 \times 200 \mathrm{ml})$, dried over magnesium sulfate and concentrated in vacuo, and the residue was purified by column chromatography on silica, eluting with $\mathrm{CH}_{2} \mathrm{Cl}_{2}$. The first major band was collected and evaporated on vacuum to give $5(7.2 \mathrm{~g}, 87 \%)$ as pale yellow flakes or needles. M.p. $=172-$ $173^{\circ} \mathrm{C}$ (lit. m.p $=174-175^{\circ} \mathrm{C}[50]$ and $172-174^{\circ} \mathrm{C}[51]$ ). ${ }^{1} \mathrm{H}$ NMR $\left(\mathrm{CDCl}_{3}\right) \delta 10.22(\mathrm{~s}, 1 \mathrm{H}), 8.98(\mathrm{~d}, 1 \mathrm{H}), 8.33(\mathrm{dd}, 1 \mathrm{H}), 8.11(\mathrm{q}, 2 \mathrm{H})$, $7.70(\mathrm{~m}, 1 \mathrm{H})$. IR (KBr): $\widetilde{v} / \mathrm{cm}^{-1}=3085 \mathrm{w}, 1710 \mathrm{ssh}, 1619 \mathrm{~m}, 1601$ m, 1548 ssh, 1533 ssh, 1503 m, 1462 m, 1429 w, 1410 w, 1363 m, 1353 msh, 1324 w, 1252 w, 1064 m, 1033 w, 998 ssh, 887 msh, 
$848 \mathrm{msh}, 810 \mathrm{msh}, 773 \mathrm{w}, 761 \mathrm{w}, 685 \mathrm{w}, 649 \mathrm{~m}$. MS: m/z (\%): 202.1 (19), 172.0 (46), 128.1 (75), 116.1 (100), 101.1 (67), 89.1 (61), 77.1 (30). Anal. Calc. for $\mathrm{C}_{10} \mathrm{H}_{6} \mathrm{~N}_{2} \mathrm{O}_{3}$ (202.17): C 59.41, H 2.99, N 13.86\%; found: C 59.82, H 3.11, N 13.54\%.

\section{8-Amino-7-quinolinecarbaldehyde (6)}

To a mixture of $5(2.6 \mathrm{~g}, 12.86 \mathrm{mmol})$ in $\mathrm{EtOH}, \mathrm{HOAc}, \mathrm{H}_{2} \mathrm{O}(2: 2: 1$, $100 \mathrm{~mL}$ ) and Fe powder ( $5.3 \mathrm{~g}, 94.90 \mathrm{mmol}$ ) was added few drops of conc. $\mathrm{HCl}$. The stirring greenish mixture was heated to reflux under $\mathrm{Ar}$ for 30 min during which time the colour turned orange. The mixture was stirred for further $30 \mathrm{~min}$ at r.t. The solution was filtered, diluted with water $(150 \mathrm{~mL})$ and extracted with $\mathrm{CH}_{2} \mathrm{Cl}_{2}(3 \times$ $100 \mathrm{~mL}$ ). The organic layer was collected, washed with saturated $\mathrm{NaHCO}_{3}(2 \times 100 \mathrm{~mL})$ and water $(2 \times 100 \mathrm{~mL})$, dried over $\mathrm{MgSO}_{4}$ then filtered. The solvent was evaporated under vacuum. A yellow oil which was obtained was purified by column (silica, eluting with $\mathrm{CH}_{2} \mathrm{Cl}_{2}$ ). The first major band was collected, evaporated on vacuum to afford 6 as a yellow oil which was crystallised upon standing at r.t. $\left(2.0 \mathrm{~g}, 90 \%\right.$ ). M.p. $=80-83^{\circ} \mathrm{C}$ (lit. m.p $=81-86^{\circ} \mathrm{C}[50]$ ). ${ }^{1} \mathrm{H}$ NMR $\left(\mathrm{CDCl}_{3}\right) \delta 9.99(\mathrm{~s}, 1 \mathrm{H}), 8.76(\mathrm{dd}, 1 \mathrm{H}), 8.03(\mathrm{dd}, 1 \mathrm{H}), 7.50(\mathrm{~m}, 2 \mathrm{H})$, $6.98(\mathrm{~d}, 1 \mathrm{H}) .{ }^{13} \mathrm{C}$ NMR $\left(\mathrm{CDCl}_{3}\right) \delta 193.03,149.00,147.53,138.36$, 135.81, 131.14, 130.22, 130.02, 124.25, 113.15. IR (KBr): $\widetilde{v} / \mathrm{cm}^{-1}=$ 3472 m, 3354 m, 2896 w, 2803 w, 1671 ssh, 1665 ssh, 1624 ssh, 1600 ssh, 1555 ssh, 1534 m, 1517 m, 1461 ssh, 1413 ssh, 1335 m, 1313 m, 1263 w, 1206 msh, 1130 msh, 948 m, 855 ssh, 830 ssh, 798 ssh, 705 msh, 674 w, 641 w. MS: m/z (\%): 172.1 (66), 145.1 (100), 117.1 (59), 89.1 (35). Anal. Calc. for $\mathrm{C}_{10} \mathrm{H}_{8} \mathrm{~N}_{2} \mathrm{O}$ (172.18): C 69.76, H 4.68, N 16.27\%; found: C 69.32, H 4.91, N 16.11\%.

\section{2-(pyrid-2'-yl)-1,10-phenanthroline (7)}

2-acetylpyridine $(0.4 \mathrm{~g}, 3.3 \mathrm{mmol}$ ) was dissolved in $50 \mathrm{~mL}$ ethanol, to which $6(0.58 \mathrm{~g}, 3.3 \mathrm{mmol})$ and $\mathrm{KOH}(2 \mathrm{~mL}$ saturated ethanolic) were added. The reaction mixture was heated to reflux under $\mathrm{Ar}$ overnight. The red brown solution was cooled, evaporated and purified on column $\left(\mathrm{SiO}_{2}\right.$, eluting with $\left.\mathrm{CH}_{2} \mathrm{Cl}_{2}: \mathrm{MeOH}(10: 1)\right)$. The first major band was collected and evaporated to afford a yellow oil $(0.63 \mathrm{~g}, 72 \%)$. M.p. $=>300^{\circ} \mathrm{C}$ (lit. m.p $=>300^{\circ} \mathrm{C}[49]$ ). ${ }^{1} \mathrm{H}$ NMR $\left(\mathrm{CDCl}_{3}\right) \delta 9.27(\mathrm{dd}, 1 \mathrm{H}), 9.02(\mathrm{~d}, 1 \mathrm{H}), 8.83(\mathrm{~d}, 1 \mathrm{H}), 8.77(\mathrm{dd}, 1 \mathrm{H})$, $8.40(\mathrm{~d}, 1 \mathrm{H}), 8.28(\mathrm{dd}, 1 \mathrm{H}), 7.94(\mathrm{dt}, 1 \mathrm{H}), 7.85-7.81$ (q, $2 \mathrm{H}), 7.66$ (dd, $1 \mathrm{H}), 7.35(\mathrm{~m}, 1 \mathrm{H})$. MS: $\mathrm{m} / \mathrm{z}(\%): 257.2(100), 229.2$ (27), 179.1 (14), 128.6 (11). Anal. Calc. for $\mathrm{C}_{17} \mathrm{H}_{11} \mathrm{~N}_{3} .1 / 2 \mathrm{CH}_{2} \mathrm{Cl}_{2}$ (299.07): C 70.12, H 4.04, N 14.02\%; found: C 70.02, H 4.64, N 14.65\%.

\section{Results and Discussion}

The synthetic chemistry of the materials described in this paper is presented in [Fig-1]. As part of our study towards the synthesis of asymmetrical ditopic bridging ligands, we synthesized tridentate terpyridyl 2-(pyrid-2'-yl)-1,10-phenanthroline (pyp) ligand (7).

The preparation of pyp (7) was straightforward using the method described below. Complete assignments of ${ }^{1} \mathrm{H}$ and ${ }^{13} \mathrm{C}$ NMR and MS spectra were made and were consistent with values given in the literature [49]. The melting point range measured for the compound was similar to that reported $\left(>300^{\circ} \mathrm{C}\right)$, and has proven reproducible over numerous preparations.

The key step of the synthesis was to prepare 7-methyl quinoline as a starting material.

As it is shown in [Fig-1], the first step undergoes a Skraup reaction which is generally considered to proceed with the intermediate formation of a $\beta$-arylaminocarboxaldehyde or a Shiff base derived from it, then cyclisation to a tetrahydroquinoline followed by elimination of water molecule and oxidation of the resulting dihydroquinoline using nitrobenzene salt [52-53]. In the presence of a strong ortho-para directing group, $-\mathrm{CH}_{3}$, it is expected that the reaction leads to 7 methylquinoline (1) only [54]. However, we observed, based on the ${ }^{1} \mathrm{H}$ NMR and GC-MS studies [Fig-2], that the 5-methylquinoline was also formed in the reaction mixture as a minor product which can be interpreted through the cyclisation mechanistic step via an either sides of the $\mathrm{NH}_{2}$ group on the ring. The mechanism of such reactions has been described [52].

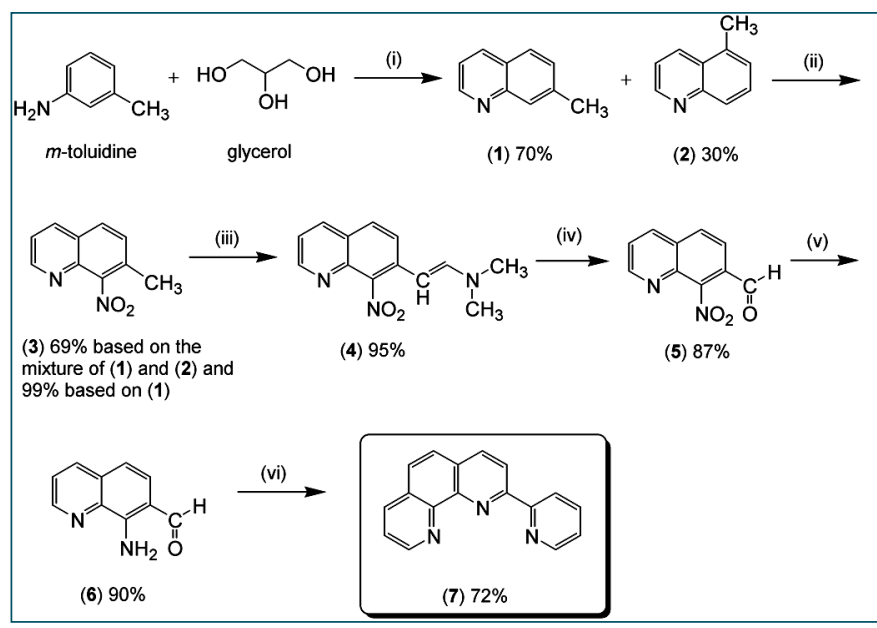

Fig. 1- Synthesis of pyp ligand (7): (i) sodium m-nitrobenzene sulfonate, $m$-toluidine, $98 \% \mathrm{H}_{2} \mathrm{SO}_{4}$ and $\mathrm{H}_{2} \mathrm{O}$, reflux; (ii) fuming $\mathrm{HNO}_{3}$ and $98 \% \mathrm{H}_{2} \mathrm{SO}_{4},-5^{\circ} \mathrm{C}$; (iii) $\mathrm{N}, \mathrm{N}$-dimethylformamide dimethyl acetal, dry DMF, under $\mathrm{Ar}, 140^{\circ} \mathrm{C}$, 24hr; (iv) $\mathrm{NaIO}_{4}, \mathrm{THF} / \mathrm{H}_{2} \mathrm{O}$, r.t, 4hrs; (v) $\mathrm{Fe} / \mathrm{HCl}$, EtOH, $\mathrm{HOAc}, \mathrm{H}_{2} \mathrm{O}$, reflux, $30 \mathrm{~min}$; (vi) 2-acetylpyridine, $\mathrm{KOH}, \mathrm{EtOH}$, under $\mathrm{Ar}$, reflux, overnight.

The chemical shifts of the proton signals associated with the protons of the methyl groups in the mixture of 7-methylquinoline (1) and 5-methylquinoline (2) in $\mathrm{CDCl}_{3}$ have been assigned at 2.5454 and $2.6482 \mathrm{ppm}$, respectively. The peaks integration interpretation suggests that the products formed with 2:1 ratio, respectively. The results also were consistent with the GC-MS analysis of the reaction mixture in chloroform solvent [Fig-2]. As it is depicted in [Fig-2], two peaks were observed in TIC Scan with peak integration of (100:50, for (1) and (2), respectively). Therefore, the product was shown to consist of a mixture of 7 -methylquinoline $(70 \%)$ and 5 methylquinoline (30\%).

Unfortunately, isolation of the predominant 7-substituted isomer using a variety of methods such as column chromatography, crystallization or distillation techniques remained unsuccessful.

It seemed probable, at the first instance, that the 7-methylquinoline (1) used in the above studies would have contained appreciable amounts of the 5-methylquinoline (2), the nitration of which would have given rise to additional products [53].

Nitration reaction of the mixture was, therefore, carried out using fuming nitric acid in conc. sulfuric acid. The product which was obtained was then analyzed by NMR and MS techniques. The ${ }^{1} \mathrm{H}$ NMR and MS studies showed that only one product was obtained. Product with a nitro group ortho to a methyl group may be identified from its MS by the facile loss of $\mathrm{OH}$ ion from the parent ion. The parent ion mass/charge ratio signal of the nitro product in GC-MS determination was 188.1, while the mass/charge ratio signal of 171.1 can be assigned as $[\mathrm{M}-\mathrm{OH}]^{+}$which was in consistent with the results reported previously for ortho-nitrotoluene [55]. 


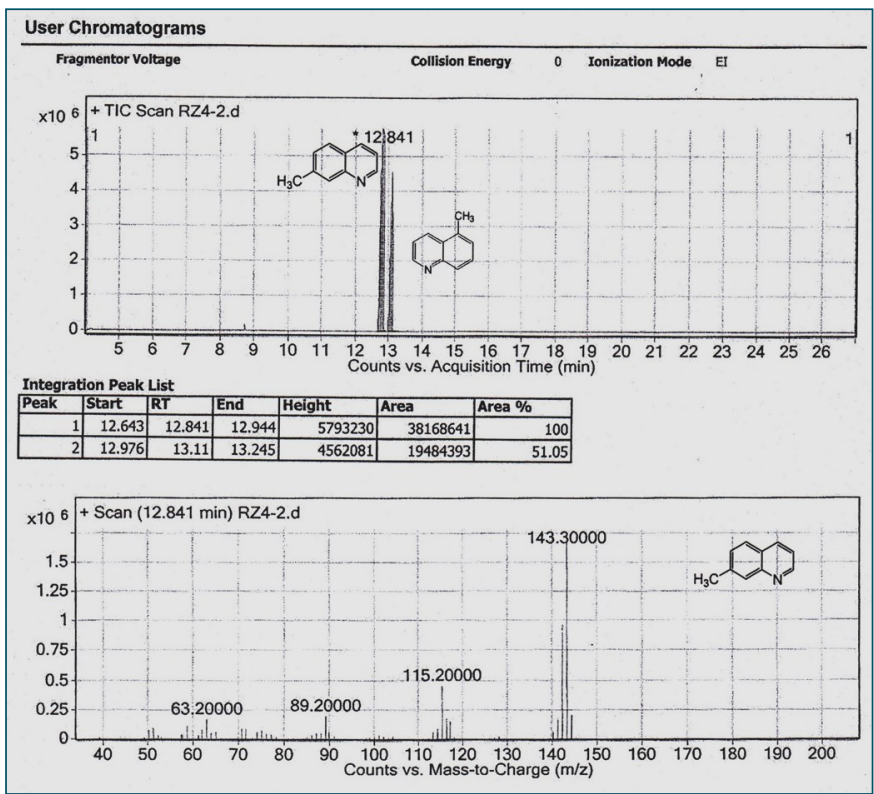

Fig. 2- GC-MS analysis of the reaction mixture of 7- and 5methylquinoline in chloroform solvent. The Chromatogram above shows the ratio of $2: 1$ in the mixture.

In our study, nitration of the mixture of 7-methyl- and 5-methylquinoline obtained by Skraup synthesis, with fuming $\mathrm{HNO}_{3}$ and concentrated $\mathrm{H}_{2} \mathrm{SO}_{4}$ gave 7-methyl-8-nitroquinoline selectively as a white pure powder product, the identity of which was confirmed by the ejection of $\mathrm{OH}$ ion from the parent ion in the MS and by a lack of significant benzylic coupling proton in the NMR spectrum. Similar studies were performed by Long and Schofield [56] using a mixture of 7-ethyl- and 5-ethyl-quinoline, but in their study, they observed the formation of a minor 5-ethyl-8-nitroquinoline as a side product by which the nitration products were contaminated and, therefore, the yield of the total synthesis decreased significantly compared to our report. In our study, in contrast, a pure selective product was formed upon nitration of the mixture of 7-methyl- and 5-methylquinoline. The formation of other products was not observed either.

Nitration of the mixture of 7-methyl-quinoline results in exclusive formation of 8-isomer, which is the only position remaining in the carboxylic ring that is fully conjugated (ortho) with the methyl group, considering the lesser degree of -character of the 6,7-bond. Based on this interpretation, nitration of 5-methyl-quinoline is to be expected to occur at both positions 8 and 6 , both position being fully conjugated (para and ortho, respectively) with the methyl group. Surprisingly, these expected products were not formed during the nitration reaction of the mixture. The total yield of nitroderivative was $99 \%$ from 7 -methylquinoline. This could be of the result of the reaction condition approach that we designed in our laboratory.

We have found the oxidation of 3 to the aldehyde 5 with selenium dioxide [57] gives variable yields; in contrast, our two-step procedure gives excellent and reproducible yields. The reaction of 3 with $\mathrm{N}, \mathrm{N}$-dimethylformamide dimethyl acetal (DMFDMA) gave the $\mathrm{N}, \mathrm{N}$ dimethylaminovinyl derivative 4 in near-quantitative yield. Subsequent modified oxidation with sodium periodate $[50,58,59]$ in aqueous THF gave 5 in high yield. These materials could be readily characterized by their ${ }^{1} \mathrm{H}$ NMR, IR and MS spectra. The ${ }^{1} \mathrm{H}$ NMR spectrum indicated a characteristic singlet assigned to proton aldehyde appearing at $\delta 10.22$. The $I R$ spectrum showed the $C=0$ stretching of the aldehyde at $1710 \mathrm{~cm}^{-1}$. The $\mathrm{C}-\mathrm{H}$ stretch for the aldehyde was also observed at 3058 and $2924 \mathrm{~cm}^{-1}$ as two medium intensity peaks which are the characteristic absorption peaks for aromatic aldehyde groups. The aldehyde 5 is the key intermediate for the preparation of the ligand 7.

A modified procedure [50] for reduction of the nitro group in compound 5 was with powdered iron in acidic medium employed to afford the corresponding amino compound 6 in high yield. The compound was fully characterized by conventional methods. A parent ion was observed at $\mathrm{m} / \mathrm{z} 172.1$ in the GC-MS spectrum.

The ${ }^{1} \mathrm{H}$ NMR and ${ }^{13} \mathrm{C}$ NMR spectra were well-resolved with a characteristic singlet assigned to the proton aldehyde appearing at $\delta$ 9.99 and a singlet assigned to the carbon aldehyde appearing at $\delta$ 193.10, respectively which were all consistent with the literature values [58].

The infrared spectra of 6 in the region between $4000 \mathrm{~cm}^{-1}$ to $200 \mathrm{~cm}$ -1 showed all the characteristic vibrations of the compound. The $\mathrm{C}=0$ Stretching of the aldehyde was observed at 1671 and $1665 \mathrm{~cm}$

${ }^{-1}$. The $\mathrm{C}-\mathrm{H}$ stretch for the aldehyde was observed at 2896 and $2803 \mathrm{~cm}^{-1}$ as two medium intensity peaks which are the characteristic absorption peaks for aromatic aldehyde groups. Two vibrational frequencies at 3354 and $3472 \mathrm{~cm}^{-1}$ were the characteristic absorptions for the $\mathrm{N}-\mathrm{H}$ stretching of the primary amine in the amine aldehyde 6 .

The Friedländer condensation approach was used for the direct construction of a pyridine ring on 6 to afford a tridentate ligand 7 . This method has been used by Thummel and his research group for the preparation of $7[49,50]$. Our improved synthesis of 7 gave a product which was characterized using NMR, GC-MS, IR, and elemental analysis methods. A parent ion was observed at $\mathrm{m} / \mathrm{z} 257.2$ in the GC-MS spectrum [Fig-3A].

The ${ }^{1} \mathrm{H}$ NMR spectrum of compound 7 exhibit eleven characteristic ${ }^{1} \mathrm{H}$ aromatic resonances which proved the structure in solution [Fig3B].

The melting point of the recrystallised material was also somehow similar to that reported in the literature $\left(>300^{\circ} \mathrm{C}\right)$ [49].

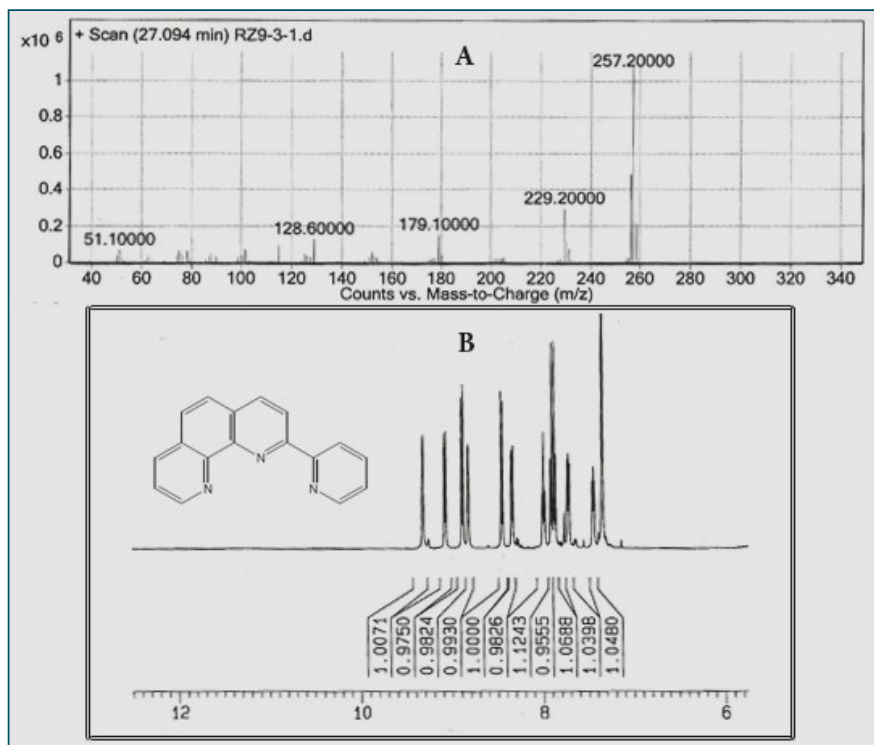

Fig. 3- (A) GC-MS analysis of (7) in chloroform solvent; (B) ${ }^{1} \mathrm{H}$ NMR spectrum of (7) in $\mathrm{CDCl}_{3}$ solvent.

\section{Conclusion}

An improved synthesis of 2-(pyrid-2'-yl)-1,10-phenanthroline as a 
tridentate terpyridyl ligand starting with Skraup synthesis of 7methylquinoline from $m$-toluidine was reported. The ligand was prepared in overall high yield.

\section{Acknowledgement}

The authors are grateful to Dr. M.H. Lashkari, Dr. A. Khoshdel, Dr. Sh. Iravani, Dr. S.J. Hosseini Shokouh and Dr. B. Dormanesh for their generous support. The authors are also indebted to Dr. F. Kobarfard of Shahid Beheshti University of Medical Sciences for his help in spectrometric and elemental analyses. Professor R.P. Thummel of The University of Houston is also gratefully acknowledged for helpful discussions.

\section{Conflicts of Interest: None declared.}

\section{References}

[1] Lehn J.M. (1995) Supramolecular Chemistry VCH, Weinheim.

[2] Collin J.P., Gavina P., Heitz V. and Sauvage J.P. (1998) Eur. J. Inorg. Chem., 1, 1-14.

[3] Constable E.C. and Thompson A.W.C. (1992) J. Chem. Soc., Dalton Trans., 2947-2950.

[4] Collin J.P., Guillerez S., Sauvage J.P., Barigelletti F., Cola L. D., Flamigni L. and Balzani V. (1991) Inorg. Chem., 30, 42304238.

[5] Coe B.J., Thompson D.W., Culbertson C.T., Schoonover J.R., Meyer T.J. (1995) Inorganic Chemistry, 34(13), 3385-3395.

[6] Cardenas D.J., Gavina P. and Sauvage J.P. (1996) Chem. Commun., 1915-1916.

[7] Hanan G.S., Arana C.R., Lehn J.M., Baum G. and Fenske D. (1996) Chem. Eur. J., 2, 1292-1302.

[8] Scolaro L.M., Romeo A. and Terracina A. (1997) Chem. Commun., 1451-1452.

[9] Grosshenny V., Harriman A., Hissler M. and Ziessel R. (1996) Platinum Metals Rev., 40(1), 26-35.

[10]Barigelletti F., Flamigni L., Balzani V., Collin J.P., Sauvage J.P. and Sour A. (1995) New J. Chem., 19, 793-798.

[11]Brothers H.M. and Kostic N.M. (1988) Inorg. Chem., 27, 17611767.

[12]Shirai H., Hanabusa K., Takahashi Y., Mizobe F. and Hanada K. (1994) PCT Int. Appl., WO 94 14440, JP Appl., 92/348, 684.

[13]Kröhnke F. (1976) Synthesis, 1, 1-24.

[14]Potts K. (1990) Bull. Soc. Chim. Belg., 99(9), 741-768.

[15]Constable E.C., Ward M.D. (1990) J. Chem. Soc., Dalton Trans., 4, 1405-1409.

[16]Constable E.C., Cargill Thompson A.M.W., Tocher D.A., Daniels M.A.M. (1992) New J. Chem., 16, 855-867.

[17]Ziessel R. (1999) Synthesis, 11, 1839-1865.

[18]Pabst G.R., Sauer J. (1999) Tetrahedron, 55(16), 5067-5088.

[19]Fallahpour R.A., Constable E.C. (1997) J. Chem. Soc., Perkin Trans., 1(16), 2263-2264.

[20]Fallahpour R.A., Neuburger M., Zehnder M. (1999) Polyhedron, 18, 2445-2454.

[21]Fallahpour R.A. (1998) Eur. J. Inorg. Chem., 1205-1207.

[22]Fallahpour R.A., Neuburger M., Zehnder M. (1999) Synthesis, $6,1051-1055$.
[23]Fallahpour R.A. (2000) Synthesis, 8, 1138-1142.

[24]Fallahpour R.A., Neuburger M., Zehnder M. (1999) Polyhedron, 18, 2445-2454.

[25]Constable E.C., Neuburger M., Smith A.P., Zehnder M. (1998) Inorg. Chim. Acta, 359-365.

[26]Constable E.C., Harverson P., Smith D.R., Whall L. (1997) Polyhedron, 16, 3615-3623.

[27]Constable E.C., Harverson P., Smith D.R., Whall L.A. (1994) Tetrahedron, 50, 7799-7806.

[28]Fallahpour R.A. (2000) Synthesis, 12, 1665-1667.

[29]Ulrich G., Bedel S., Picard C., Tisnes P. (2001) Tetrahedron Lett., 42, 6113-6115.

[30]Fallahpour R.A., Neuburger M., Zender M. (1999) New J. Chem., 23(1), 53-61.

[31]Ziessel R., Suffert J., Youinou M.T. (1996) J. Org. Chem., 61, 6535-6546.

[32]El-ghayoury A., Ziessel R. (2000) J. Org. Chem., 65, 77577763.

[33]Encinas S., Flamigni L., Barigelletti F., Constable E.C., Housecroft C.E., Schofield E.R., Figgemeier E., Fenske D., Neuburger M., Vos J.G., Zehnder M. (2002) Chem. Eur. J., 8, 137-150.

[34]Hartshorn R.M., Zibaseresht R., Robinson W.T. (2005) Acta Cryst., E61, m981-m983.

[35]Zibaseresht R. and Hartshorn R.M. (2005) Dalton Trans., 38983908.

[36]Zibaseresht R. and Hartshorn R.M. (2006) Acta Cryst., E62, i19 $-i 22$.

[37]Zibaseresht R., Robinson W.T., Hartshorn R.M. (2006) Acta Cryst., E62, m1150-m1153.

[38]Zibaseresht R., Downward A.M. and Hartshorn R.M. (2010) Aust. J. Chem., 63, 669-679.

[39]Thornley P.A., Starkey J.C., Zibaseresht R., Polson M.I.J., Wiakira J.L. and Hartshorn R.M. (2011) J. Coordination Chem., 64 (1), 145-158.

[40]Hjelm J., Handel R. W., Hagfeldt A., Constable E. C., Housecroft C. E. and Forster R. J. (2005) Inorg. Chem., 44(4), 10731081.

[41]Benniston A.C., Grosshenny V., Harriman A. and Ziessel R. (2004) Dalton Trans., 8, 1227-1232.

[42]Baranoff E., Collin J.P., Flamigni L. and Sauvage J.P. (2004) Chem. Soc. Rev., 33, 147-155.

[43]Amini A., Harriman A. and Mayeux A. (2004) Phys. Chem. Chem. Phys., 6, 1157-1164.

[44]Schubert U.S. and Hofmeier H. (2002) Macromol. Rapid Commun., 23, 561-566.

[45]Gohy J.F., Lohmeijer B.G.G. and Schubert U.S. (2002) Macromolecules, 35, 4560-4563.

[46]Xiang-Hong L., Qiang L.Z., Fu-You L., Xin-Fang D. and ChunHui H. (2007) Chin. J. Chem., 25(2), 186-189.

[47]Chisholm M.H., Hada C.M., Heinze K., Hempel K., Singh N., Vyas S. (2008) J. Cluster Sci., 19(1), 209-218.

[48]Liang Z.Q., Wang C.X., Yang J.X., Gao H.W., Tian Y.P., Tao X.T. and Jiang M.H. (2007) New J. Chem., 31(6), 906-910. 
[49]Hung C., Wang T., Shi Z. and Thummel R.P. (1994) Tetrahedron, 50, 10685-10692.

[50]Riesgo E.C., Jin X. and Thummel R.P. (1996) J. Org. Chem., 61, 3017-3022.

[51]Danikiewicz W. and Makosza M. (1985) Tetrahedron Lett., 26, 3599-3600.

[52]Jack L.J. (2003) Name Reactions (A Collection of Detailed Reaction Mechanism), Springer-Verlag, Germany, 378-379.

[53]Palmer M.H. (1962) J. Chem. Soc., 3645-3652.

[54]Bradford L., Elliott T.J. and Rowe M. (1947) J. Chem. Soc., 437445.

[55]Beynon J.H., Saunders R.A. and Williams A.F. (1968) Mass Spectra of Organic Molecules, 325-330.

[56]Long R. and Schofield K. (1953) J. Chem. Soc., 2350-2354.

[57]Imperiali B., Prins T.J. and Fisher S.L. (1993) J. Org. Chem., 58, 1613-1616.

[58]Vetelino M.G. and Coe J.W. (1994) Tetrahedron Lett., 35(2), 219-222.

[59]Dupau P., Renouard T. and Le Bozec H. (1996) Tetrahedron Lett., 37, 7503-7506. 